\title{
Application of Lean Manufacturing in Hospitals-the Need to Consider Maturity, Complexity, and the Value Concept
}

Hasle, Peter; Nielsen, Anders Paarup; Edwards, Kasper

Published in:

Human Factors and Ergonomics In Manufacturing

Link to article, DOI:

10.1002/hfm.20668

Publication date:

2016

Document Version

Peer reviewed version

Link back to DTU Orbit

Citation (APA):

Hasle, P., Nielsen, A. P., \& Edwards, K. (2016). Application of Lean Manufacturing in Hospitals-the Need to Consider Maturity, Complexity, and the Value Concept. Human Factors and Ergonomics In Manufacturing, 26(4), 430-442. https://doi.org/10.1002/hfm.20668

\section{General rights}

Copyright and moral rights for the publications made accessible in the public portal are retained by the authors and/or other copyright owners and it is a condition of accessing publications that users recognise and abide by the legal requirements associated with these rights.

- Users may download and print one copy of any publication from the public portal for the purpose of private study or research.

- You may not further distribute the material or use it for any profit-making activity or commercial gain

- You may freely distribute the URL identifying the publication in the public portal 


\title{
Application of lean manufacturing in hospitals - the need to consider ma- turity, complexity and values
}

\author{
Hasle, Peter ; Nielsen, Anders Paarup ; Edwards, Kasper \\ in journal: Human Factors and Ergonomics in Manufacturing (ISSN: 1090- \\ 8471) (DOI: http://dx.doi.org/10.1002/hfm.20668), 2016
}

\begin{abstract}
Lean is widely applied in hospitals but the impact tend to be limited. This paper investigates three possible explanations: maturity, complexity and the value concept and analyses the bearing of these in a case study of lean application in a large Danish university hospital. The results indicate that lean tends to be applied in secondary and support functions with a logistic character, and therefore has had a limited impact on the overall healthcare performance. The case study show that there are constraints related to low lean maturity, the complexity of processes and operations as well as differences in value perceptions among the different professions within the hospital. The conclusion is that lean is useful for hospitals, but the lean concept as well as its implementation methods need to be fitted to the organisational complexity and diverging values in hospitals in order to bring about a larger impact. It is therefore necessary to develop new models for the lean concept as well as the implementation of lean adapted to the particular context of hospitals with a stronger focus on patient experiences and on coordination of social relations.
\end{abstract}

\section{Keywords}

Healthcare, lean management, productivity, maturity, complexity, value

\section{Introduction}

Healthcare systems - especially hospitals - in Denmark and other industrialised countries face serious challenges, including rapid growth in demands in terms of the number of patients, 
quality expectations, shorter waiting times and the application of new expensive treatments. At the same time, they also face restricted budgets, which is further enhanced by the economic crisis, and there is therefore a need to utilise the scarce resources effectively and efficiently. Hospitals are ever searching for possible solutions to increase productivity, and many operations management concepts have been tried such as quality circles (Lees \& Dale, 1989), Total Quality Management (Kaluzny, McLaughlin, \& Simpson, 1992) and others (Marjoua \& Bozic, 2012). In recent years the principles of lean manufacturing have received growing popularity as a possible answer to the challenges in the sector (Radnor, Holweg, \& Waring, 2012), and in a Danish context, lean is the dominating rationalisation approach in hospitals. The academic literature on lean in hospitals has been growing steadily since the turn of the millennium, and after more than 10 years of lean in hospitals the time has come to assess the prospects for a broader integration of lean into hospitals.

It is not obvious that lean can serve as a general solution to improve the utilisation of scarce resources in hospitals. Lean manufacturing was developed in the motor industry (Spear \& Bowen, 1999; Womack \& Jones, 1996) and is based on standardisation, levelling, and optimisation of work flows which are not necessarily applicable in hospitals. Reviews of the literature on lean in hospitals seem to confirm that lean is not easily fitted to the reality of hospitals (Holden, 2011; Mazzocato, Savage, Brommels, Aronsson, \& Thor, 2010; Vest \& Gamm, 2009). Although the application of lean is still growing (Burgess, 2013) there seems to be a disproportion between the popularity of lean in hospitals and the limited effect - at least so far. The aim of this paper is to seek possible explanations for this problem and to assess whether lean is applicable to such an extent that it can contribute considerably to solving the challenges facing hospitals.

We use the available literature to find possible explanations for the challenges in fitting lean to hospitals and suggest maturity, complexity and ambiguities in the value concept as important possibilities. We further study these aspects in an analysis of the lean implementation at a large Danish university hospital to assess whether the explanations play a role in practical lean implementation. We conclude that lean has the potential to contribute positively to hospital development, but must be matured and reconstructed in such a way that it can be 
integrated into the core process in hospitals today. A stronger focus on the patient in order to integrate operational value with clinical and experiential value and considerations of the professional and social relations in hospitals are important elements in a version of lean with a stronger fit to hospitals.

\section{Lean in healthcare}

Lean and lean inspired improvement methodologies are receiving tremendous attention in hospitals and is now being widely adopted within the healthcare sector (de Souza \& Pidd, 2011; de Souza, 2009; Radnor et al., 2012). There seems to be general agreement that lean offers huge opportunities for making improvements within healthcare (Spear, 2005), and the number of scientific papers about lean in hospitals is growing rapidly (de Souza, 2009; Leggat et al. 2015).

Many papers paint a rather positive picture of the application of lean in hospitals (See for example Ballé \& Régnier, 2007; Ben-Tovim, Bassham, \& al., 2007; Graban, 2008; Neufeld et al., 2013). A number of books add to this picture. They all agree on the large prospects for lean in hospitals and report successful case stories and provide recipes for lean implementation (Aherne \& Whelton, 2010; Kenny, 2011; Miller, 2005).

The introduction of lean in hospitals has often been described as a straightforward process and some even advocate following the original approach, developed by Toyota, as closely as possible (Graban, 2008). However, this literature does not discuss the possible constraints for the application of a concept originally developed in the automobile industry into the hospital sector. Still, the many case studies describing positive achievements can be interpreted as an indication of possible benefits for lean in hospitals. These possible benefits seem to have caught the interest of healthcare managers and policy makers, but they appear to contrast with the realised benefits, which are currently questioned. Reviews of the literature on lean in hospitals point in a similar direction. The first one (Vest \& Gamm 2009) uses rigorous research criteria in a systematic review, and the authors conclude that the evidence for the benefits of lean and other similar effectiveness transformation strategies are weak, although pointing in a positive direction. Holden (2011) and Mazzocato et al. (2010) also point towards a positive 
effect, but Holden emphasises that the documentation of effects is generally limited and mainly linked to patient satisfaction, whereas Mazzocato et al. conclude that most lean changes are of narrow technical or tool-based scope and have limited organisational reach. Andersen et al. (2014) point towards lack of evidence and suggest ways to develop the studies of lean in hospitals, whereas Leggat et al. (2015) in a recent review found that most published papers on in lean in hospitals lacked research rigour, but also that positive effects were identified when lean (described as part of reengineering) was integrated with HRM and proper change management.

Most published lean implementations have focused on improving support of peripheral activities - for example administrative procedures, laboratory work and the logistics of consumables (See the review in Edwards, Nielsen, \& Jacobsen, 2012). These lean projects have yielded quite good results in terms of cost savings and process improvements. Cases addressing the core activities of the hospital are few and have mostly focused on improving the flow of patients through an emergency department, primarily in order to reduce waiting time for the patients. Furthermore, most of the reviewed cases have applied a 'tool-driven' approach to lean in which only a limited number of tools from the lean toolbox were deployed (Edwards et al., 2012).

However, large scale productivity results of lean still need to manifest themselves. Most of the positive stories in papers and books depict experience from the stakeholders responsible for implementation of lean or are written by stakeholders with an interest in advocating lean. This tendency to have a biased discussion of lean where focus is on successful lean implementations (Holden, 2011) may create failure myopia (Levinthal \& March, 1993), leading to a gap in the literature concerning the optimal approach to implementing lean in hospitals.

In sum, the literature points towards a rather fragmented application of lean in hospitals. From the literature two problems can be observed. Firstly, lean is mostly limited to secondary support functions. Secondly. lean implementations relies on a few proven lean tools, whereas traditional key elements of lean, such as flow, pull and standardisation, have been little used especially in the core functions and processes of the hospital. These two problems in combination leads to the abovementioned fragmented application of lean in the hospital - lean may 
typically only exist in isolated 'islands'. There are a few case hospitals which may point towards a broader application - most obvious Virginia Mason (Kenney, 2011). However, it is not clear why these hospitals have been more successful in a deeper lean implementation, and how this experience can be achieved by other hospitals.

The limited and fragmented application contrasts the popularity of lean in hospitals, creating a paradox which needs to be resolved if it should be possible for lean to make a stronger contribution to the future development of hospitals.

It is pointed out by Radnor and Holweg (2010) that lean 'is not a context-free methodology and so transfer without adaptation is bound to deliver very limited, focal results that will pale into insignificance compared to what lean has achieved in the manufacturing world'. Application of lean without proper adaptation may end up in what Radnor, Holweg, and Waring (2012) describe as a ‘disjointed application’ of lean.

We propose three possible explanations for the limited scope of lean in healthcare: The first explanation is lack of adaptation or rather the immaturity of lean in healthcare, the second one is the contrast between the imperative of lean to simplify work and the complex nature of hospitals and the third one is the ambiguity of what is value and to whom in hospitals. We discuss in the following sections based on the literature these three possibilities as possible explanations for the constraints for the wider lean application in hospitals, and then we follow up by analysing the significance of the explanations in a practical case study.

\subsection{The immaturity of lean in healthcare}

Lean management in the hospital sector has had a relatively short lifespan compared to the lifespan of lean in the automobile industry. Although focus on efficiency and quality in hospitals have a much longer history, the first examples of lean implementation appeared after the Millennium and more widespread application is only found during the last years. Most of the applications are therefore rather limited use of the lean tool box (Edwards et al., 2012; Radnor et al., 2012). It is possible that sufficient time will create the experience necessary for a more successful and deeper implementation of lean in all functions and processes of the hospital. In this understanding, it would be required to allow lean sufficient time to develop an applicable 
and consistent body of knowledge and experiences (i.e. a set of best practices for the application of lean in hospitals). It would therefore take a substantial amount of time to experience the same high levels of lean penetration in hospitals as currently experienced in the manufacturing sector. Looking at the historical development of lean manufacturing at Toyota, it can be traced back more than 40 years (Holweg, 2007); and a long gestation or implementation period was necessary also at Toyota before lean management emerged in its current form.

Furthermore, industrial companies have been working with ideas now incorporated into the 'lean toolbox' for many years; for example, scientific research on productivity development and standardisation in manufacturing can be dated back at least to the works of Frederick W. Taylor (1911). As such, many of the different concepts and tools that are associated with lean have been present in productivity improvement in manufacturing companies for a long period of time. Efficiency and especially quality also have a long history at hospitals, but it is issues mainly related to clinical practices and only to a limited extent to operational productivity which has been a strong focus in the manufacturing industry. However, examples can be traced back to the early times of scientific management where pioneers did time and motion studies in surgery. These examples did not have an impact similar to manufacturing, and only recently have there been a sharp rise in academic and practitioner-oriented research on lean in the hospital sector. But, the scattered picture and short lifespan of lean in hospitals are also hampering research (Andersen et al., 2014; 2014, p. Curatolo et al.) Maturity is used as a term for assessing the level of lean in organisations (Wong, Ignatius, \& Soh, 2014), and lean must therefore be considered at a low maturity stage in hospitals. However, it is not just a question of time and accumulation of practical experience in the process of maturing lean in hospitals, it is - as for manufacturing which developed tailored tools and methods - necessary to develop lean methods which fit the peculiarities of hospital, and that is where complexity and value systems become crucial concepts.

\subsection{Complexity}

Hospitals are among the most complex of modern organisations (Plsek \& Greenhalgh, 2001). This complexity has a number of sources. First, effective treatment requires individually tai- 
lored treatment plans and patients often have multiple conditions (comorbidity), with possible interaction between treatment regimens. Treatment flows at hospitals will therefore exhibit what some researchers have called causal ambiguity (See for example Lippman \& Rumelt, 1982), making it difficult to identify unambiguous causal relations between treatment and patient reactions to treatment. Second, the intake of acute patients is to a large extent unpredictable in terms of numbers and diseases, thereby among other things creating the need for certain level of slack capacity. Third, most hospitals are organised in functional silos in order to harness the benefits of specialization, making it difficult to create coherent and seamless patient flows and pathways, thereby leading to role conflicts and ambiguity within the organisation (Perrow, 1986; Rizzo, House, \& Lirtzman, 1970). Finally, many processes in a hospital are dependent on the coordination of actors from different professions (Plsek \& Wilson, 2001).

It is important to distinguish the concept of 'complexity' from that of 'being complicated' (Rogers, 2008): a complicated process, such as producing a car or constructing a major bridge, has many elements, but they are all in principle predictable, whereas complexity means that the outcome of the interaction between the many elements is to some extent unpredictable. Furthermore, the hospital system is exhibiting causal ambiguity, making it impossible to fully forecast the behaviour of patients and their response to treatments. According to Stacey, Griffin, and Shaw (2000), complex systems are characterized by unpredictability and paradoxes, and it must be accepted that some things will remain unknowable. The system will in some situations operate on 'the edge of chaos', where the value of planning and standardised procedures is limited, knowledge is dynamic and not static, and actors must be able to improvise and solve problems as they move along. Based on these ideas Plsek and Greenhalgh (2001, p. 625) state that 'new conceptual frameworks that incorporate a dynamic, emergent, creative, and intuitive view of the world must replace traditional "reduce and resolve" approaches to clinical care and service organisation'. As such, the inherent complexity of the hospital can be a significant barrier to lean, as this complexity challenges some of the basic principles - and indeed the foundation - of lean which require predictability in order to standardise processes, level demand, and create flow. This is arguably also the reason for the wide 
application and success of lean in support functions such as logistics, labs, X-ray and pharmacies, which share close resemblances to traditional manufacturing activities and thus are easier to predict and standardise whereas lean in more complex emergency operations is hampered by complexity (Mazzocato et al., 2014).

\subsection{The value concept}

The third and final issue focuses on problems in identifying a single conception of value. A common and shared definition of value is the key prerequisite for a successful implementation of lean, and indeed is the very foundation for lean. While value for the customer is a reasonably clear concept in industrial settings, it is not yet so in hospitals (Young \& McClean, 2008). The hospital context makes it difficult to define a rigorous value concept. One explanation for this problem is multiple stakeholders' different rationalities (Glouberman \& Mintzberg, 2001a, 2001b). Nurses focus on care, doctors on cure, managers on operational performance and, lastly, the trustees focus on value for the surrounding community. These four rationalities have inherently different perceptions of value, and Young and McClean (2008) follow up by suggesting that there are at least three dimensions to value relevant for the application of lean in hospitals:

- Clinical value (the best patient outcome);

- Experiential value (patients’ experience of care);

- Operational value (the greatest cost-effectiveness).

Young and McClean furthermore argue that most of the emphasis in the lean projects described in the literature so far has focused on the operational value, and doctors and nurses have difficulty understanding the merits of operational value compared to their focus on clinical and experiential value. It is also evident that lean improvements on one type of value, especially the operational value of cost-effectiveness, might conflict with one or both of the other values.

\section{Methodology}


We now turn to empirical evidence of the possibilities for widespread application of lean in hospitals. We have studied lean implementation in Odense University Hospital which is selected as an extreme case according to Flyvbjerg (2001) because it is renowned for the most comprehensive lean implementation among the Danish hospitals. It should therefore be an example of how far lean can reach at the present stage in Danish hospitals. It is an embedded case study (Yin, 2009) as we make detailed studies of the cancer department. It is representing one of the larger specialities without immediate and simple standardisation possibilities. The case study methods is particularly appropriate in this context because the empirical inquiry makes it possible to capture these details of lean practice "within its real-life context" (Yin, 2009, p. 18). The case study was one of nine cases in a larger research project aimed at the integration of lean and work environment improvements but not healthcare specifically (Edwards, Bojesen, \& Nielsen, 2010; Hasle, 2010)

Data about the general lean strategy at the hospital were collected through interviews with the CEO and two consultants from the central lean support unit, participant observation of the lean training courses and collection of written material.

The case study in the cancer department had a prospective design where the researchers followed the lean implementation from its initial stages until it was formally completed and subsequently followed the sustainability of changes. In the cancer department qualitative data were collected about lean activities and staff reactions towards lean. The data collected included observation of key activities such as introductory lean training, kaizen meetings and steering committee meetings. Observation data was captured as field notes and written material such as minutes, handouts, lean analysis and training material were collected.

Individual and group interviews were conducted with employees involved in or affected by lean and included management, doctors, nurses, secretaries, lab technicians and members of the lean project group. This ensured that only data from respondents with hands-on lean experience were collected to avoid pollution by hearsay.

Semi-structured interview guides were prepared for all interviews adapted to the specific interview respondents. The interview guides were developed on the basis the literature on lean implementation and consequences for the work environment. They covered information about the respondents work, involvement in lean and experience with lean including among others achieved results, encountered problems, relations to colleagues and managers, consequences 
for the work environment, sustainability of changes. The point of departure was the issues the department had selected to address in the lean implementation and the respondents were asked about concrete examples and events in order to avoid generalized opinions. Altogether, 21 interviews of 30 to 90 minutes' duration were carried out in the cancer department. All interviews were transcribed.

The in-depth case study was carried out in the period January 2008-April 2009. Followup activities were followed through written materials (minutes and reports) and telephone interviews until June 2010. An additional follow-up with telephone interviews to both the cancer department and the lean support department was made in January 2012 in order to assess the embodiment of early lean results and the future priority of lean at the hospital.

The initial analysis was carried out as a content analysis (Weber, 1990) assisted by coding in Nvivo. The main focus of the coding was on problems and achievement. These were subsequently tracked across interviews, observations and written material in order to create a narrative which illustrates barriers and possibilities for lean implementation. It uses the sequence of events and comparison in order to elicit and convey the essence of the analysis (Stake, 2000, pp. 435-454). Thereby the qualitative analysis tracks key events in the project and, to understand the reasons for certain events and their relations, we have examined how the respondents interpreted and attributed meaning to these events. These narratives were subsequently analysed for the significance of the implementation strategy, lean maturity, complexity and understanding of values. The validity of the data collection and analysis was strengthened by the focus on concrete events, the prospective design and the possibility to triangulate between many different respondents, direct observations and written material.

\section{Findings}

The university hospital has more than 10,000 employees and has integrated lean into its overall strategy (Karstoft \& Tarp, 2011). Lean has been a strategic priority for the hospital and considerable resources have been committed to lean implementation since 2006. An internal lean support unit with seven consultants organised lean implementation in waves of five to six departments, each lasting a year. A wave started with an intensive training course of eight sessions lasting three days each for the departmental lean implementation groups. 
Local implementation was based on a strong element of employee involvement, and during and after the course, a consultant from the unit was attached to each department for 6-12 months. The hospital implemented four waves with 18 departments and 4,000 employees in the period 2006-2010. The lean strategy of the hospital changed in 2010 from the above mentioned wave approach, where departments were enrolled in lean without much choice, to a more targeted approach where departments work with lean based on their own motivation and get support from lean consultants as needed. In addition, the lean support unit runs basic and advanced courses in lean which are open to all managers and employees.

The hospital has not conducted an overall evaluation of the effects of lean at the hospital. The lean support unit explains that the implementation activities are so different and are influenced by so many other change activities that it is not possible to make a generalised effect evaluation - lean is just one project among many other projects within the hospital. Both management and the lean unit consider lean to have provided large benefits at the hospital which, among other things, is reflected in the fact that lean is integrated in the new strategy for the hospital prepared after a change of managing director in 2009. The unit has in addition collected a large number of concrete improvements which build, among others, upon an extensive use of kaizen boards, kaizen events, standardisation of procedures, value stream mapping and 5S. One example is the results seen in the radiology department (Karstoft \& Tarp, 2011), one of the first wave departments. Here the department succeeded in achieving substantial productivity improvements as well as embedment of continued lean activities. In the overall assessment of the first wave of lean, the head of the lean unit estimates that one-third of the departments experienced a strong effect following the integration of lean in operation and development, one-third experienced some effect and one-third experienced a limited effect. He considered an important constraint for the achievement of a stronger effect to be that doctors and, to some extent, nurses consider lean to have little relevance for their core treatment and care tasks. He also explained that the change from the wave approach was caused by negative reactions to the centralized control.

\subsection{Lean implementation in the cancer department}


The cancer department has 350 employees and includes wards, outpatient chemotherapy, radiation therapy, a laboratory and a palliative section. As part of the lean project, a steering committee was established with the head nurse, the head consulting doctor, the leader of the lean project group and the consultant from the lean unit. A lean project group was organised with a nurse as project leader and, in addition, a consulting doctor, two nurses, a secretary, a lab technician and a radiologist.

The change strategy was based on extensive involvement of the staff. Before the project commenced, intensive information activities were undertaken, including meetings in the collaborative committee, staff meetings and written material. All change activities involved the staff concerned, in some cases in the form of kaizen workshops over one or two halfdays, when representatives of the staff analysed selected problems using value stream mapping and came up with solutions. In other cases, working groups with the staff concerned were established to analyse a particular problem and come up with a solution.

A relatively large number of issues were addressed. The main ones concerned delivery of chemotherapy medicine, collaboration between lab technicians and the chemotherapy outpatient clinic, handling of blood samples, handling of case records, elimination of unnecessary telephone calls, establishment of kaizen boards, the reorganisation of patient booking in the chemotherapy outpatient clinic and reorganisation of the ward rounds.

Several changes which the actors describe as successful i.e. described in positive terms as working well and supporting their work were implemented. This included higher quality of medicine delivery, improved management of blood samples and medical records, reduction in telephone calls, use of kaizen boards with many implemented suggestions and reorganisation of the lab technicians' work; but the reorganisation of the patient booking in the chemotherapy outpatient clinic in particular turned out to be very problematic, and the department was still fighting to get the patient booking back on track when the project ended. Similarly, the reorganisation of the ward rounds was never implemented. Four key issues can be used to illustrate the scope for lean: delivery of chemotherapy medicine; kaizen boards; patient booking at the outpatient clinic; and reorganisation of ward rounds. 


\subsubsection{Delivery of chemotherapy medicine}

Patients in the outpatient clinic were called in for treatment at a specific time, but the clinic had for years experienced large groups of patients waiting because medicine was not ready when they arrived. Quarterly meetings between management of the department and of the hospital pharmacy had not been able to solve the problem. A kaizen event facilitated by the lean project leader and with participation from two clinic nurses and two pharmacy assistants carried out a value stream mapping of the information and medicine flow. It turned out that the pharmacy scheduled production in the same sequence that the medicine was ordered by the clinic which, in turn, was ordered as results of blood tests the day before treatment. However, the sequence of ordering was not equal to the sequence in which patients arrived for treatment. As a result, medicine for afternoon patients was ready in the morning and medicine for morning patients was often not ready. A simple procedure for mutual information solved the problem. The pharmacy was informed about patient meeting time and the clinic about absenteeism and other production problems in the pharmacy in order to learn about expected delays. The result was the almost complete removal of waiting patients, and less medicine was wasted because of no-show patients. Furthermore, the nurses at the cancer ward no longer had to spend time making rush-orders to the pharmacy in order to get the medicine they needed for the waiting patients. The follow-up in 2012 indicated that the solution to the problem was still working and that the collaboration with the pharmacy had been further strengthened.

\subsubsection{Kaizen boards}

The department introduced kaizen boards in all wards and sections. The procedure was a short weekly meeting collecting ideas for improvements which were placed on the board with a person responsible for follow-up. Ideas were then implemented straight away, transformed into projects or discarded. The kaizen boards had reasonable success. During a period of one and a half years, 457 suggestions were recorded, 347 of which were implemented and 37 transformed into regular projects. However, the results in different sections were mixed. The lab, radiation therapy and secretaries' sections had the highest number of suggestions and the staff were enthusiastic about the kaizen boards. They felt that they had received a valuable 
tool for the improvement of their work. In the lab, the staff reported that they had used the suggestions to reorganise the layout, creating more space in a rather congested area, and had reorganised the ordering of supplies, avoiding delays due to lack of materials. For the wards, the kaizen boards did not really work; for the outpatient clinic, results were mixed, with a reasonable number of suggestions but problems cropped up with maintaining commitment to the boards. Generally, it proved to be difficult to get doctors engaged in the kaizen boards and the doctors would always prioritize treatment and care related activites. The kaizen boards were mainly concerned with administrative processes which had little influence on the doctors work. By 2012 the kaizen boards had run out of steam and were no longer used. Even in the most enthusiastic section - the lab - the boards were cancelled after a change of the lab manager.

\subsubsection{Booking system in the outpatient clinic}

One issue for the lean implementation was to create a more systematic planning of patient flow in order to utilise treatment facilities more efficiently. A prerequisite for the lean changes was a new IT-programme for patient booking. Among other things, the new system would make it possible to plan patient booking for the expected duration for each individual chemotherapy treatment, which can vary considerably. It turned out that the technical side of the IT implementation was much more complicated than expected, and for quite some time there were technical problems with the bookings which pushed the lean implementation to the background. But the new booking system also changed the work of the nurses. Previously the nurses individually booked their own patients, whereas now they were supposed to ask a secretary to do the booking. They explained that the new system created more work, partly because of the technical problems and partly because they had to get in touch with a secretary rather than doing the booking themselves. On top of this, quite a number of the nurses felt their professionalism was challenged. Nurses focused on the individualised care of the patient and construed booking to be part of this approach, as they had the possibility to take individual consideration of patients' preferences for meeting times (See further details in Hasle, 2010).

The booking system is fully working in 2012 and the conflicts are long gone. After extend- 
ed discussions, booking is now carried out by the nurses once again. The management of the department recognised that the nurses develop an intimate understanding of each patient, which is important when planning and booking the patient's treatment. The booking system has now expanded to cover all bookings and a number of other planning activities in the department, and it has been organised in such a way that it can be utilised as expected by the lean project. It should be noted that the new booking system as such was not formally part of the lean project but, as it was running parallel with the lean activities, many nurses associated the booking system with lean and used the IT problems to give lean a negative label.

\subsubsection{Reorganisation of ward rounds}

Despite this being named a priority activity, it was never initiated. The staff and in particular the doctors focussed on the obstacles. Among the most important ones was a decision from the Danish government about higher priority to cancer treatment which included a right to treatment 48 hours after diagnosis. Therefore all new patients had to be treated as acute patients, and doctors were continuously called for conferences at other departments such as radiology and surgery. The ward round is typically done by junior doctors who, in some cases, would need to consult the consulting doctors - who were most often tied to other tasks and were not available. This would halt the ward round as no decision regarding the particular patient could be made. Every attempt to plan ward rounds more efficiently failed, as senior doctors were regularly missing. From the senior doctors perspective the ward round was not acute and more acute patients were given priority subsequently reorganizing the ward round was not prioritized. At the time of the follow-up the department had decided to merge the two wards into one ward with approximately 40 beds. The head nurse explained that they used some of the lean tools to identify bottlenecks and 5S for the physical design, and that they hoped to solve the problem with the ward rounds through this merger.

\subsubsection{Evaluation of lean at the cancer department}

The overall results are mixed. The initial one-and-a-half-year implementation experienced several important achievements, most remarkably better supply of medicine and reduced wait- 
ing times in the outpatient clinic, but there were also areas which saw no results. The results of these implementations seem still to be working in 2012; the conflicts related to the booking system have been resolved and it now works as planned. However, lean has not become part of the 'modus operandi' in the department. The lean group has been discontinued and kaizen meetings have stopped.

There are probably several explanations for this, some of which have to do with the implementation strategy and not with lean as such. The department followed most of the recommendations for lean implementation (Graban, 2008), such as top management commitment and employee involvement, but two problems can be singled out. The first is the understanding of lean as a project among other projects in the department. Lean implementation was initiated by the lean support unit and thus was a project which would end after one or two years; the lean group was subsequently discontinued after this period, indicating limited long term management support for the lean initiative. The second problem is integration in day-today operations. Kaizen meetings were established as additional meeting activities and most staff already considered meetings a burden. Kaizen events were not integrated into existing meetings. Most sections and teams have either daily or weekly deliberations where they plan activities and some of these meetings could have been adjusted to encompass the kaizen board meeting. These problems may be related to lean at a low maturity level. Lean is considered as project and as an additional activity which is not integrated in the daily operations.

However, limitations in lean implementation are only part of the explanation. Conflicting value perceptions also played an important role. First and foremost, doctors (and a considerable number of nurses) never understood the potential of lean for their core activities. The doctors considered lean to be of operational value, without any relevance to their clinical value, and simply abstained from participation in the lean activities. Doctors did not participate in kaizen meetings and did not involve themselves in the reorganisation of the ward round project, even though this was a core activity for doctors.

The department management was well aware of this and tried to overcome the problem by having a doctor participate in the lean group, but he did not succeed in convincing his colleagues to take a stronger interest in lean. Similar problems were experienced in the more 
successful project in the radiology department.

Lastly, the complexity of the doctors' work posed a specific constraint in the lean project. Whereas the nurses have reasonably stable assignments to certain tasks at a specific location within the ward, doctors' work is less stable, and is a mix of pre-planned, unscheduled or short-term scheduled work, working with acute patients and in consultation with doctors from other departments. This made it difficult to make the doctors participate in lean-related meetings, which they perceive as unimportant for their clinical value and therefore give low priority.

\section{Discussion}

We began this paper by suggesting a disproportion between the popularity of lean and the limited application of lean especially in core treatment and care functions of the hospital. We suggested three possible explanations: a low maturity level due to the few years with practical experience of lean, complexity of hospital operations and parallel value perceptions. We used the case study of an extensive lean implementation in the university hospital to scrutinize whether and how these explanations played a role in the outcome of the lean implementation.

For the low lean maturity level, the case study indicate that the short time span of lean experience did play an important role. The top management and the internal lean unit developed a general implementation strategy and the necessary support function in accordance with the recommendations in the lean literature. Employees were involved to a great extent, extensive training was provided with introduction to practical tools, and qualified consultants supported implementation in the departments. This strategy provided many positive examples, but as the study of the cancer department revealed, it was difficult for the staff to take lean in. Lean became a project among many others, and the key staff, first and foremost doctors but to some extent also nurses, could not see the benefits for their treatment and care core tasks. The hospital has taken the consequence of this experience and changed to a more local implementation strategy.

The complexity of the hospital organisation also seems to be important. The most positive results were experienced in the logistic functions such as medicine delivery which have lim- 
ited complexity and is run by support staff. In the more complex activities involving doctors and nurses such as ward rounds, lean changes never appeared. The doctors' work proved to be fluctuating between known and partly planned activities and short term unplanned tasks. Doctors showed high flexibility in giving priority to the most acute tasks and still solve other tasks in between. This point is even enhanced by the advances in technology, treatment regimens and demographics which increases the need for intense care as well as treatment of comorbidity chronic diseases. Patients in the hospital today are in constant risk of experiencing deteriorating conditions requiring an immediate response from staff. Even for the nurses in the outpatient clinic the individual consideration for the patients conflicted with the lean approach to effective patient booking.

The conflict about who should make the booking is therefore also a value conflict between an operational value and the experience value. The operational value focuses on optimising the use of specialised nurses by moving the task to secretaries and through the development of standardised booking procedures to get the optimal utilisation of couches. The experience value focuses on the care of patients, such as securing a booking schedule which fits the patient's preferences and which foresees potential problems at the next treatment. Generally, the parallel and more or less overlapping or conflicting value system appear as an important constraint for the further development of lean. Especially the doctors consider lean cater only for the operational value and thus a matter for management and support staff. In the Cancer department they simply abstained from participation both in kaizen meetings and the attempt to make ward rounds more effective. Also nurses considered in some cases the lean operational value as problematic in particular for the case with patient booking.

These three suggestions seem to provide valid explanations for the limited broad scale penetration of lean in hospital. Whereas it may be possible for lean maturity to evolve over time, it may only happen if lean is sufficiently adapted to the complexity and value perceptions. They cannot be resolved by just building on the general lean literature or the positive stories from single case implementation of lean in hospitals. We will therefore turn to a discussion of the possibilities for a further adaption of lean to the special context of hospitals.

Implementing lean successfully will require that a number of different perspectives are 
deployed in conjunction. Drawing on the contingency perspective (Lawrence \& Lorsch, 1967), it is necessary to adapt and implement lean taking the specific context and contingencies of the typical hospital into account, including little experience with lean, high levels of complexity and diverging values. The main challenge is to merge the challenges of complexity and differentiating values with the principles of lean thinking. The doctors and nurses are trained in a high degree of flexibility and responsive decision-making. They are ready almost instantly to attend to the most important acute problems at hand and, at the same time, to fill out available working time with relevant tasks when the pressure from unpredicted events eases. The staff are thus qualified in handling complexity, and they do that on the basis of clinical and experiential values for the patients as customers. The staff's management of complexity and, at the same time, the fulfilment of clinical and experiential values requires extensive collaboration and coordination between different individuals, different professions and different units. Doctors, nurses and other professions share information; they give and receive advice, pass on tasks to each other and undertake joint activities. This coordination is becoming even more important as doctors and nurses become more specialised, the number of alternative diagnoses increases and still more patients develop chronic diseases with multiple diagnoses. We will therefore suggest the further development of lean to be integrated with two perspectives: Focus on the patient and the coordination of professional and social relations.

\subsection{Focus on the patient}

It is necessary with a stronger integration of the competing value systems, and one opportunity would be to develop a more transparent patient perspective. Whereas focus on the patient has always be crucial in hospitals, the traditional perspective has been that the professions (doctors and nurses) know what is best for the patients, and in the lean context doctors and nurses tend to consider operational value as conflicting with their assessment of clinical and experiential value. In addition, in most cases, lean is handled as an internal activity which is not subject to direct patient involvement. An explicit focus on patient needs and involving patients in defining these needs (Elwyn et al., 2012) can be used to develop interprofessional joint reflections as well as staff - management reflections, thereby increasing the possibility 
to develop shared values. Clinical care pathways (Rotter et al., 2010) is another possibility of securing focus at the patient at the same time as it can provide a tool for staff for organisation of their work. The point of departure for a reorganisation of ward rounds could thus be the clinical care parthway which could be used to overcome the constraints for organisation of the doctors work. It would subsequently be possible to develop a a joint understanding between the different professions of the patient needs regarding information and decisions during ward rounds. Thereby it could be possible to avoid the staff experience of lean biased towards resource optimization without consideration of clinical and care needs.

\subsection{Coordination of professional and social relations}

The idea is that a large amount of coordination between individuals, professions and organisational units are necessary every day at hospitals. Social relations between people are therefore crucial. This concept has recently been suggested as a key approach to efficient hospitals (Gittell, 2009). Gittell suggest the core points to be shared goals, shared knowledge and mutual respect which facilitate communication which is timely, relevant and problem solving. Improvement of relational coordination may also facilitate development of stronger integration of value systems as professions increase their understanding of the other professions values.

Many lean tools such as value stream mapping and kaizen can be useful in the development of value integration and relational coordination. Also standardized procedures related to for instance visual management and short standing meetings (huddles) can provide the structures necessary for sustaining activities.

\section{Conclusion}

Do the observations in this paper indicate that the implementation of lean within hospitals should be limited to peripheral activities such as laboratory work and the management of consumables? The answer to this question is no - lean provides opportunities for making significant improvements within all areas of a hospital. However, is it not just a question of letting a sufficient amount of time pass for lean to mature and thereby adapted to the hospital sector. In 
order to realise the full potential of lean in the hospital sector it is necessary to adapt lean tools and concepts to the special characteristics of the hospital; that is, the complexity inherent in many processes and activities, as well as the problems in establishing a shared understanding of value. It has proven particular difficult to involve doctors in the lean activities whom give priority to patient related activites. A strengthened focus on the patient and the patients' voice will help to integrate the value systems, and that should work alongside increased coordination of social and professional relations. These two approaches can again be supported by the application of a number of lean tools.

There is, therefore, a need for what might be referred to as a transformative approach to lean. The principles of lean are sound but it is necessary to adopt a more experimental approach, with a focus on re-contextualising lean to the realities of hospitals in order to be successful with implementation. This reflects the need for the development of more knowledge about lean and to utilize the existing experience better, as stated in the first explanation for the limited application of lean in hospitals. Furthermore, lean must be complemented with additional methodologies and tools with focus on core values, relations and structures in order to realise its full potential.

\section{References}

Aherne, J., \& Whelton, J. (2010). Applying lean in healthcare: A collection of international case studies. New York: Productivity Press.

Andersen, H., Røvik, K. A., \& Ingebrigtsen, T. (2014). Lean thinking in hospitals: is there a cure for the absence of evidence? A systematic review of reviews. BMJ Open, 4(1), e003873. http://doi.org/10.1136/bmjopen-2013-003873

Ballé, M., \& Régnier, A. (2007). Lean as a learning system in a hospital ward. Leadership in Health Services (Bradford, England), 20(1), 33-41. http://doi.org/10.1108/17511870710721471

Ben-Tovim, D. I., Bassham, J. E., \& al., et. (2007). Lean thinking across a hospital: redesigning care at the: Flinders Medical Centre. Australian Health Review, 31(1), 10 15. Retrieved from refman0834

Burgess, N. (2013). Evaluating lean in healthcare, 26(3), 220-235. http://doi.org/10.1108/09526861311311418 
Curatolo, N., Lamouri, S., Huet, J.-C., \& Rieutord, A. (2014). A critical analysis of Lean approach structuring in hospitals. Business Process Management Journal, 20(3), 433454.

de Souza, L. (2009). Trends and approaches in lean healthcare. Leadership in Health Services, 22(2), 121-139. Retrieved from http://dx.doi.org/10.1108/17511870910953788

de Souza, L., \& Pidd, M. (2011). Exploring the barriers to lean health care implementation. Public Money \& Management, 31(1), 59-66.

Edwards, K., Bojesen, A., \& Nielsen, A. P. (Eds.). (2010). Lean og arbejdsmiljø - et dynamisk spcendingsfelt. København: L\&R Business.

Edwards, K., Nielsen, A. P., \& Jacobsen, P. (2012). Implementing lean in surgery - lessons and implications. International Journal of Technology Management, 57(1-3), 4-17. Retrieved from WOS:000298302800001

Elwyn, G., Frosch, D., Thomson, R., Joseph-Williams, N., Lloyd, A., Kinnersley, P., ... Barry, M. (2012). Shared decision making: A model for clinical practice. Journal of General Internal Medicine, 27(10), 1361-1367. http://doi.org/10.1007/s11606-012-2077-6

Flyvbjerg, B. (2001). Make social science matter: Why social inquiry fails and how it can succeed again. Cambridge: Cambridge University Press.

Gittell, J. H. (2009). High performance health care - using the power of relationship to achieve quality, efficiency and resilience. New York: McGraw-Hill.

Glouberman, S., \& Mintzberg, H. (2001a). Managing the care of health and the cure of disease - part 1: Differentiation. Health Care Management Review, 26(1), 56-71.

Glouberman, S., \& Mintzberg, H. (2001b). Managing the care of health and the cure of disease - Part II: Integration. Health Care Management Review, 26(1), 70-84. Retrieved from WOS:000167036400007

Graban, M. (2008). Lean hospitals: improving quality, patient safety, and employee satisfaction. Boca Raton, FL: CRC Press.

Hasle, P. (2010). Professional assessment and collective standards - lean in a cancer department. In P. Vink \& J. Kantola (Eds.), Advances in occupational, social, and organizational ergonomics (pp. 345-354). CRC Press / Taylor \& Francis Ltd. Retrieved from Refman0866.pdf

Holden, R. J. (2011). Lean Thinking in Emergency Departments: A Critical Review. Annals of Emergency Medicine, 57(3), 265-278. Retrieved from WOS:000288345800016

Holweg, M. (2007). The genealogy of lean production. Journal of Operations Management, 25(2), 420-437. Retrieved from ISI:000245527600016

Kaluzny, a D., McLaughlin, C. P., \& Simpson, K. (1992). Applying total quality management concepts to public health organizations. Public Health Reports, 107(3), 257-264. 
Karstoft, J., \& Tarp, L. (2011). Is Lean Management implementable in a department of radiology?, 2(3), 267-273. Retrieved from http://dx.doi.org/10.1007/s13244-010-0044-5

Kenney, C. (2011). Transforming Health Care: Virginia Mason's Pursuit of the Perfect Patient Experience. New York: Productivity Press.

Kenny, C. (2011). Transforming health care: Virginia Mason Medical Center's pursuit of the perfect patient experience. New York: Productivity Press.

Lawrence, P. R., \& Lorsch, J. W. (1967). Differentiation and Integration in Complex Organizations. Administrative Science Quarterly, 12(1), 1-47. Retrieved from http://search.ebscohost.com/login.aspx?direct=true\&db=buh\&AN=4079860\&site=ehostlive

Lees, J., \& Dale, B. G. (1989). The Use of Quality Circles in a Health Care Environment. International Journal of Health Care Quality Assurance, 2(2), 4-12. http://doi.org/10.1108/EUM0000000001991

Leggat, S. G., Bartram, T., Stanton, P., Bamber, G. J., \& Sohal, A. S. (2015). Have process redesign methods, such as Lean, been successful in changing care delivery in hospitals? A systematic review. Public Money \& Management, 35(2), 161-168. http://doi.org/10.1080/09540962.2015.1007714

Levinthal, D. A., \& March, J. G. (1993). The Myopia of Learning. Strategic Management Journal, 14, 95-112. Retrieved from WOS:A1993NK89800008

Lippman, S. A., \& Rumelt, R. P. (1982). Uncertain Imitability - An Analysis of Interfirm Differences in Efficiency Under Competition. Bell Journal of Economics, 13(2), 418438. Retrieved from WOS:A1982PX95100010

Marjoua, Y., \& Bozic, K. J. (2012). Brief history of quality movement in US healthcare. Current Reviews in Musculoskeletal Medicine, 5(4), 265-273. http://doi.org/10.1007/s12178-012-9137-8

Mazzocato, P., Savage, C., Brommels, M., Aronsson, H., \& Thor, J. (2010). Lean thinking in healthcare: a realist review of the literature. Quality \& Safety in Health Care, 19(5), 376382. Retrieved from WOS:000285032700004

Mazzocato, P., Thor, J., Bäckman, U., Brommels, M., Carlsson, J., Jonsson, F., ... Savage, C. (2014). Complexity complicates lean: lessons from seven emergency services, 28(2), 266-288.

Miller, D. (2005). Going lean in healthcare,. Cambridge, MA: Institute for Healthcare improvement.

Neufeld, N. J., Hoyer, E. H., Cabahug, P., González-Fernández, M., Mehta, M., Walker, N. C., ... Mayer, R. S. (2013). A Lean Six Sigma Quality Improvement Project to Increase Discharge Paperwork Completeness for Admission to a Comprehensive Integrated Inpatient Rehabilitation Program. American Journal of Medical Quality, 28(4), 301-307. 
http://doi.org/10.1177/1062860612470486

Perrow, C. (1986). Complex organizations - a critical essay (Vol. 3th editio). New York: McGraw-Hill.

Plsek, P. E., \& Greenhalgh, T. (2001). Complexity science - The challenge of complexity in health care. British Medical Journal, 323(7313), 625-628. Retrieved from WOS:000171087300026

Plsek, P. E., \& Wilson, T. (2001). Complexity science - Complexity, leadership, and management in healthcare organisations. British Medical Journal, 323(7315), 746-749. Retrieved from WOS:000171340700026

Radnor, Z. J., \& Holweg, M. (2010). From tools to systems: a critical appraisal of lean healthcare implementations. In Managing Operations in Service Environments, 17th EurOMA Conference, Porto, Portugal, 3rd--7th June 2010.

Radnor, Z. J., Holweg, M., \& Waring, J. (2012). Lean in healthcare: The unfilled promise? Social Science \&amp; Medicine, 74, 364-371. Retrieved from http://www.sciencedirect.com/science/article/pii/S0277953611000979

Rizzo, J. R., House, R. J., \& Lirtzman, S. I. (1970). Role conflict and ambiguity in complex organizations. Administrative Science Quarterly, 15(2), 150-162. Retrieved from WOS:A1970H239200003

Rogers, P. J. (2008). Using programme theory to evaluate complicated and complex aspects of interventions. Evaluation, 14(1), 29-48. Retrieved from refman0879.pdf

Rotter, T., Kinsman, L., James, E., Machotta, A., Gothe, H., Willis, J., ... Kugler, J. (2010). Clinical pathways: effects on professional practice, patient outcomes, length of stay and hospital costs. The Cochrane Database of Systematic Reviews, 7(3), CD006632. http://doi.org/10.1002/14651858.CD006632.pub2

Spear, S. J. (2005). Fixing health care from the inside, today. Harvard Business Review, 83(9), 78-91. Retrieved from WOS:000231550800020

Spear, S. J., \& Bowen, H. K. (1999). Decoding the DNA of the Toyota production system. Harvard Business Review, 95-106. Retrieved from refman0812

Stacey, R., Griffin, D., \& Shaw, P. (2000). Complexity and management: fad or radical challenge to systems thinking. London: Routledge.

Stake, R. E. (2000). Case Studies. In N. K. Denzin \& Y. S. Lincoln (Eds.), Handbook of qualitative research (pp. 435-454). Thousand Oaks: Sage.

Taylor, F. W. (1911). Scientific management. New York: Harper \& Brothers.

Vest, J. R., \& Gamm, L. D. (2009). A critical review of the research literature on Six Sigma, Lean and StuderGroup's Hardwiring Excellence in the United States: the need to demonstrate and communicate the effectiveness of transformation strategies in 
healthcare. Implementation Science, 4. Retrieved from ISI:000268171800001

Weber, R. P. (1990). Basic content analysis. Sage University Papers.

Womack, J. P., \& Jones, D. T. (1996). Lean thinking. New York: Simon \& Schuster.

Wong, W. P., Ignatius, K. L., \& Soh. (2014). What is the leanness level of your organisation in lean transformation implementation? An integrated lean index using ANP approach. Production Planning \& Control, 25(4), 273-287.

Yin, R. K. (2009). Case study research: Design and methods. London: Sage Publications.

Young, T. P., \& McClean, S. I. (2008). A critical look at lean thinking in healthcare. Quality and Safety in Health Care, 17(5), 382-386. 